\title{
Anti-Helicobacter pylori activity of acomplex mixture of Lactobacillus paracasei HP7 including the extract of Perilla frutescens var. acuta and Glycyrrhiza glabra
}

\author{
Hyun-A Lee ${ }^{1}$, Joo-Yun Kim², Jisoo Kim², Bora Nam² and Okjin Kim ${ }^{1 *}$ (0)
}

\begin{abstract}
The effect of standard therapeutic strategies on Helicobacter pylori infection is diminished over time owing to the emergence of drug resistant strains. In this study, we would like to confirm the enhanced effect of L. paracasei HP7, which has been reported to exert antibacterial and gastric mucosal protective effects, in combination with Perilla frutescens var. acuta (P. frutescens)and Glycyrrhiza glabra (G. glabra) extracts.

$P$. frutescens extract and G. glabra extract were found to inhibit the growth of $H$. pylori in a concentrationdependent manner, and the combination of L. paracasei HP7 and P. frutescens extract and G. glabra extract effectively inhibited $H$. pylori from attaching to AGS a gastric epithelial cells. Moreover, L. paracasei HP7 complex mixture containing $P$. frutescens and G. glabra extracts has been shown to inhibit $H$. pylori virulence genes such as AlpA, CagA, FlaA and UreA. When H. pylori-infected mice were administered a complex mixture of L. paracasei HP7 containing $P$. frutescens and G. glabra extract, the infection rate of $H$. pylori was significantly reduced. In addition, the L. paracasei HP7 complex mixture significantly reduced serum IL-8 levels and stomach inflammation in H. pylori infected mice.

These results suggest that a complex mixture of L. paracasei HP7 containing P. frutescens and G. glabra extracts may be an alternative to treating diseases caused by $H$. pylori infection.
\end{abstract}

Keywords: Lactobacillus paracasei, HP7, Helicobacter pylori, Perilla frutescens var. acuta, Glycyrrhiza glabr

\section{Introduction}

Helicobacter pylori, a major causative pathogen of chronic gastritis [1] and gastric ulcers [2], is a spiral of gram-negative bacteria associated with an increased risk of gastric cancer [3, 4]. Vaccination with antibiotics to remove gastric $H$. pylori can reduce $H$. pylori-associated gastrointestinal diseases $[5,6]$ and reduce the risk of gastric cancer [7]. The standard recommended therapy for H. pylori uses two antibiotics, usually a triple

\footnotetext{
* Correspondence: kimoj@wku.ac.kr

${ }^{1}$ Center for Animal Resources Development, Wonkwang University, 460 Iksandae-ro, Iksan 54538, Republic of Korea

Full list of author information is available at the end of the article
}

combination therapy, including clarithromycin and a proton pump inhibitor with amoxicillin or metronidazole $[8,9]$. However, the efficacy of the triple therapy has currently reduced over time. Recent cure rates of less than $80 \%$ are mainly due to the increased prevalence of resistant $H$. pylori strains in metronidazole and clarithromycin [10-12]. In addition, some patients showed allergic side effects to antibiotics and can sometimes cause side effects if H. pylori is not treated [13]. Longterm vaccination with antibiotics is not recommended for the prevention of $H$. pylori infection. Therefore, it is important to develop new non-antibacterial agents for the treatment of H. pylori [14]. 
Lactobacillus spp. is recommended as an additive to the standard recommended treatment for $H$. pylori treatment, and it is possible to improve the patient's adaptability by reducing the side effects of antibacterial agents $[15,16]$. In our previous study, we reported that the lactic acid bacterium Lactobacillus paracasei HP7 (L. paracasei HP7) isolated from kimchi, a fermented vegetable dish widely consumed in Korea, had inhibitory effects against $H$. pylori in-vitro and in-vivo [17].

Recently, there has been a clear increase in demand for natural compounds from plant extracts that are effective antibacterial agents against a wide range of bacteria to control human infection and for the preservation of food [18]. Recently, the inhibitory effect of Glycyrrhiza glabra (G. glabra) on $H$. pylori and the therapeutic effect on infected patients have been reported [19-21]. In addition, antibacterial activities [2224] and anti-inflammatory [25-27] effects of Perilla frutescens var. acuta (P. frutescens) have been reported.

In this study, we aimed to determine whether the combination of L. paracasei HP7 and P. frutescens and G. glabra extracts had a synergistic effect on the inhibition of $H$. pylori infection.

\section{Methods/experimental}

\section{Bacterial strains}

L. paracasei HP7 was incubated at Man-Rogosa-Sharpe broth (Difco Laboratories, Detroit, Mich.) at $35^{\circ} \mathrm{C}$ for 24 h. H. pylori strain SS1 (B0890; Korean Jeongeup Korean Collection) was cultured overnight at $37^{\circ} \mathrm{C}$. under microaerobic conditions in brain-heart infusion medium containing $10 \%$ fetal bovine serum (FBS) and grown to density $\sim 2.0 \times 10^{9} \mathrm{CFU} / \mathrm{mL}$. The cultured bacteria were then transferred to phosphate buffered saline (PBS) before the test.

\section{Herbal extract}

Each of the herbal extracts of G. glabra and P. frutescens were obtained from Korea Yakult Co., Ltd.

\section{Cell culture}

Human gastric cell line AGS cells (human gastric adenocarcinoma) were obtained from the Korean Cell Line Bank (cellbank.snu.ac.kr) and used. For maintenance and proliferation of cells, passage was performed every 2 days at $37^{\circ} \mathrm{C}$ and $5 \% \mathrm{CO}_{2}$ using Ham's F-12 medium containing $10 \%$ FBS and $1 \%$ antibiotic. For analysis of $H$. pylori infection to gastric cells, antibiotics were not added to the culture medium.

\section{H. pylori growth inhibition}

To confirm the anti-H.pylori activity of P. frutescens and G. glabra extracts, Alamar blue assay was performed by referring to the study of Tsukasa $\mathrm{M}$ et al. [28]. H. pylori was suspended in DMEM / F-12 containing $5 \mathrm{mM}$ L-lactic acid with a turbidity of $0.005\left(1 \times 10^{5} \mathrm{CFU} / \mathrm{mL}\right)$. One hundred microliter suspension was added to 96 well culture plate and then incubated for $4 \mathrm{~h}$ at $37{ }^{\circ} \mathrm{C}$ with the test material ( $P$. frutescens and G. glabra extracts) under micro-aerophilic conditions. After incubation, inhibition of $H$. pylori growth was measured by Alamar blue according to manufacturer's criteria (Alamar Bio-Sciences, Sacramento, CA, U.S.A.). H. pylori inhibitory activity of the tested material was calculated by the following formula:

$$
\text { inhibition }(\%)=[(\mathrm{A}-\mathrm{B}) /(\mathrm{A}-\mathrm{C})] \times 100
$$

A: cultured without test sample. B: cultured with test sample. C: medium alone.

\section{Inhibition of $\boldsymbol{H}$. pylori adhesion to AGS cells}

AGS cells were cultured in 6-well plates for $16 \mathrm{~h}$. When the cells reached $90 \%$ confluence, the medium was replaced with serum and antibiotics-free F-12 medium. An overnight cultured $H$. pylori SS1 was suspended in Ham's F-12 medium. For co-culture of bacteria and gastric epithelial cells, $H$. pylori SS1 $\left(10^{7} \mathrm{CFU}\right)$ were added to wells containing $10^{6}$ AGS cells and incubated for $4 \mathrm{~h}$ in the absence or presence of herbal extracts and $L$. paracase $\mathrm{HP7}$. The adhesion of $H$. pylori was measured using a Real-Time PCR system (Applied Biosystems, Foster City, CA, USA) as in our previous paper [17]. Forward and reverse sequences of primers for amplifying the $H$. pylori $16 \mathrm{~S}$ RNA gene were as follows: $5^{\prime}-\mathrm{TCG}$ GAA TCA CTG GGC GTA A-3' and 5'-TTC TAT GGT TAA GCC ATA GGA TTT CAC-3'.

\section{Detect of $H$. pylori virulence gene expression}

H. pylori SS1 cells were cultured in brain-heart infusion broth at $\sim 1.0 \times 10^{7} \mathrm{CFU} / \mathrm{mL}$. Cultured $H$. pylori were treated with G. glabra extract $(3 \mu \mathrm{g} / \mathrm{mL}), P$. frutescens extract $(25 \mu \mathrm{g} / \mathrm{mL})$, and $L$ paracasei $\mathrm{HP7}\left(1.0 \times 10^{7} \mathrm{CFU} /\right.$ $\mathrm{mL}$ ) and incubate at $37^{\circ} \mathrm{C}$ for $2 \mathrm{~h}$. cDNA was synthesized using murine leukemia virus reverse transcriptasptase with random hexamer. Primer sequence for $H$. pylori virulence genes are listed in Table 1. AlpA is genes that $H$. pylori attaches to the gastric mucosa, and CagA plays the role of $H$. pylori invading gastric cells. FlaA is related to the mobility of $H$. pylori, and UreA is genes that $H$. pylori uses to neutralize gastric acid [29].

\section{Animals}

Specific pathogen free (SPF) male C57BL/6 mice weighing 20-24 g were purchased from Samtako Co. (Osan, Korea) and were maintained at the inspection facility of Wonkwang University (Iksan, Korea) for 1 week before experiments. Thereafter, the mice were maintained in an 
Table 1 PCR primer sequence for $H$. pylori virulence genes

\begin{tabular}{llll}
\hline Gene name & Sequence & Tm ( $\left.{ }^{\circ} \mathbf{C}\right)$ & Reference \\
\hline alpA & F: AAACCGCTCTGTGGATATGG & 55.0 & NP009259.1 \\
& R: GAACTGGAAGTGCGTGTATTG & 45.6 \\
cagA & F: TCACTCTTGGCGATATGGAAAT & 57.5 \\
& R: ACACAGAAGACAGAGCGTTATT & 57.7 \\
& F: GCTAAGAGCATCAATGTGGTTC & 58.3 \\
ureA & R: CGGTAACATCGCGCAAATTC & 58.5 \\
& R: AAGTGGTATTGAAGCGATGTT & 57.6 \\
\hline
\end{tabular}

SPF barrier room with regulated temperature $\left(23^{\circ} \mathrm{C} \pm\right.$ $\left.1{ }^{\circ} \mathrm{C}\right)$ and humidity $(50 \% \pm 5 \%)$ and a $12: 12$-h light/dark cycle. The animals were fed a sterilized pellet diet (Purina, Seoul, Korea) and sterilized water ad libitum. All studies were performed in accordance with the Guide for Animal Experimentation of Wonkwang University and were approved by the Institutional Animal Care and Use Committee of Wonkwang University (approval no. WKU 2019-08-22).

\section{H. pylori inoculation}

Animals were intragastrically inoculated three times, with a 3-day interval between inoculations, with $H$. pylori at $\sim 1.0 \times 10^{9} \mathrm{CFU}$ in $0.5 \mathrm{~mL}$ broth. The challenged animals were confirmed as $H$. pylori-positive by stool antigen analysis using the Bioline $H$. pylori Ag kit (Standard Diagnostics, Suwon City, Korea) as previously described [30].

\section{In vivo study protocol}

The inhibition of $H$. pylori growth by L. paracasei HP7 was investi in a mouse model. The mice were divided into six groups: negative control (NC, $n=10) ; H$. pyloriinfected without treatment $(\mathrm{C}, n=10) ; H$. pylori-infected with positive control Deglycyrrhizinated Licorice (DGL) [20] treatment (D, $n=10) ; H$. pylori-infected with P. frutescens extract (PFE) $5 \mathrm{mg} / \mathrm{kg}+$ G. glabra extract (GGE) $1.2 \mathrm{mg} / \mathrm{kg}$ (COM 1, n=10); H. pylori-infected with PFE $10 \mathrm{mg} / \mathrm{kg}+\mathrm{GGE} 1.2 \mathrm{mg} / \mathrm{kg}(\mathrm{COM} 2, \mathrm{n}=10)$; and $H$. pylori-infected with $L$. paracasei HP7 $2.0 \times 10^{7} \mathrm{CFU}+\mathrm{PFE}$ $10 \mathrm{mg} / \mathrm{kg}+\mathrm{GGE} 1.2 \mathrm{mg} / \mathrm{kg}$ (COM 3, n=10). All substances were administered orally once daily for 4 weeks. At the end of the experiment, the animals were euthanized with ether, and then dissected. The stomach was further incised along the taiwanese valley, and washed with saline. The remaining portion was formalin fixed and inserted into paraffin for histological analysis. $H$. pylori colonies were confirmed by the aforementioned quick urease test (CLO-test) [30].

\section{Blood analysis}

Blood samples were collected from the hearts of sacrificed animals,centrifuged at $1000 \times g$ for $15 \mathrm{~min}$ at $4{ }^{\circ} \mathrm{C}$, and the isolated plasma was stored at $-80^{\circ} \mathrm{C}$. Serum titers of anti- $H$. pylori antibodies were measured using a mouse anti-H. pylori antibody (IgG-1) ELISA kit (Cusabio Biotech, Wuhan, China) in accordance with the manufacturer's instructions. IL-8 levels in mice were measured using the Mouse Interleukin 8 ELISA Kit (R\&D System, Minneapolis, USA) in accordance with the manufacturer's instructions.

\section{Statistical analysis}

Experimental results were compared between groups using Minitab (State College, PA, USA) and one-way ANOVA, a parametric multiple comparison procedure. The results were expressed as mean \pm standard error and statistically significant when $P<0.05$.

\section{Results}

\section{H. pylori growth inhibition}

We measured the $H$. pylori growth inhibitory activity of 140 plant extracts including G. glabra and P. frutescens. Excluding non-edible plants, G. glabra and P. frutescens extracts showed the best inhibitory effect on the growth of $H$. pylori. In particular, G. glabra $90 \%$ ethanol extract and $P$. frutescens 50\% ethanol extract showed high activity (data not shown).

There have been several reports of antibacterial and Helicobacter pylori inhibitory activity of $P$. frutescens and G. glabra [19-24]. However, there have been few reports of synergistic effects of $H$. pylori inhibitory activity of $P$. frutescens and G. glabra. Therefore, the $H$. pylori growth inhibitory activity of each of the $P$. frutescens extract (PFE) and G. glabra extracts (GGE) was investigated, and whether the two extracts had a synergistic effect on $H$. pylori inhibition was examined. PFE and GGE inhibited the growth of $H$. pylori in a concentration-dependent manner. PFE and GGE almost completely inhibited the growth of H. pylori at concentrations of $12.5 \mu \mathrm{g} / \mathrm{mL}$ and $50 \mu \mathrm{g} / \mathrm{mL}$, respectively, and the $\mathrm{IC}_{50}$ of each extract was $23.84 \mu \mathrm{g} / \mathrm{mL}$ 
and $2.88 \mu \mathrm{g} / \mathrm{mL}$. (Fig. 1a). When the extract corresponding to $\mathrm{IC}_{50}$ was co-treated, the growth of $H$. pylori was inhibited by about $90 \%$ (Fig. 1b). This suggests that $P$. frutescens and G. glabra are synergistic in inhibiting the growth of $H$. pylori.

\section{Suppression of $H$. pylori adhesion to gastric epithelial cells}

In a previous study, we confirmed that hp7 inhibits Helicobacter pylori adhesion to gastric epithelial cells [17]. The complex mixture of $L$. paracasei HP7 containing PFE and GGE significantly inhibited $H$. pylori adhesion to gastric cells than L. paracasei HP7 or PFE or GGE

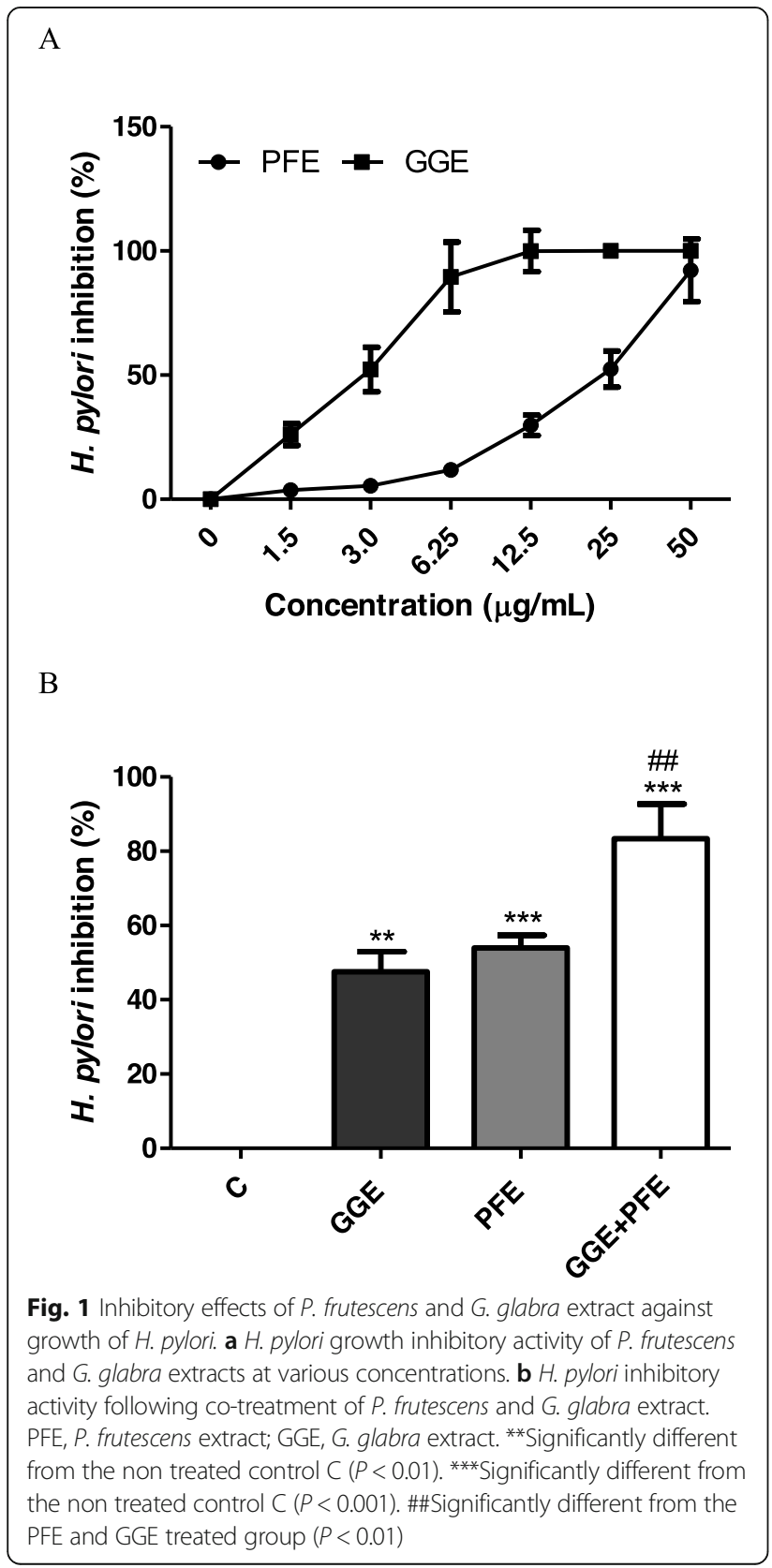

alone (Fig. 2a). These results demonstrate that L. paracasei HP7 and P. frutescens and G. glabra extracts are synergistic in inhibiting bacterial adhesion to gastric epithelial cells.

\section{Inhibition of $H$. pylori virulence factor}

H. pylori produces urease to decompose the urea in the stomach, reduce the acidity around it, move using flagella, and attach to epithelial cells through adhesion factors such as AlpA. In addition, the CagA protein secreted by $H$. pylori inflames gastric epithelial cells and

A

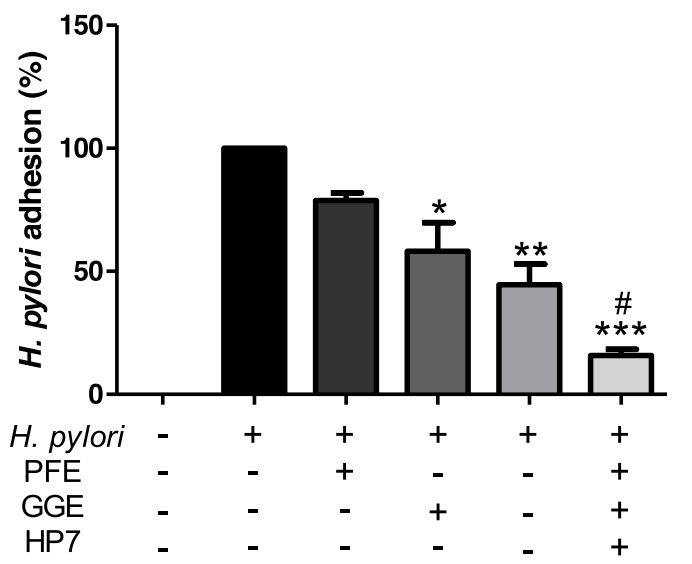

B

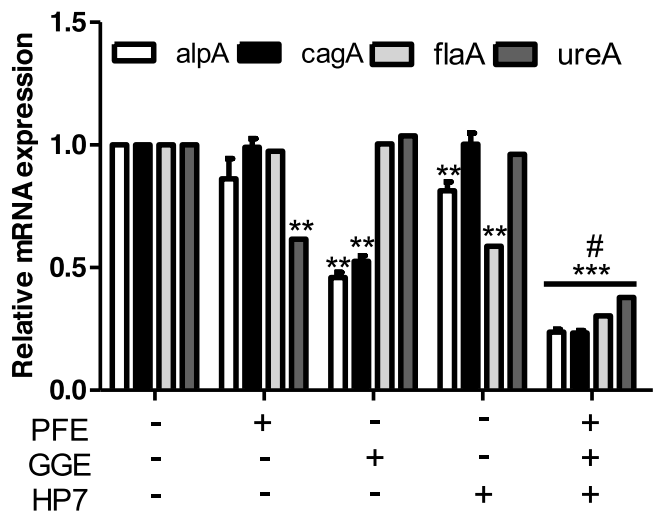

Fig. 2 Effect of complex mixture of L. paracasei HP7 containing $P$. frutescens and G. glabra extract on H. pylori adhesion and H. pylori virulence genes expression (a) Degree of $H$. pylori attached to AGS cells (b) alpA, cagA, flaA and ureA mRNA expression in L. paracasei HP7, P. frutescens extract, G. glabra extract and complex mixture treated $H$. pylori SS1. PFE, P. frutescens extract $25 \mu \mathrm{g} / \mathrm{mL} ; \mathrm{GGE}, \mathrm{G}$. glabra extract $3 \mu \mathrm{g} / \mathrm{mL}$; HP7, L. paracasei HP7 1.0 × 107 CFU/MI. *Significantly different from nontreated control $C(P<0.05)$. ${ }^{*}$ Significantly different from the non-treated control $C(P<0.01)$. ${ }^{* *}$ Significantly different from the non-treated control $C(P<0.001)$. \#Significantly different from the PFE, GGE and HP7 treated group $(P<0.05)$ 
causes gastric cell changes known as the "hummingbird phenomenon" $[1,2,29]$. Therefore, we investigated the effect of a complex mixture of L. paracasei HP7 containing PFE and GGE on the mRNA expression of genes encoding AlpA, Cag, FlaA, and UreA of $H$. pylori.

PFE significantly reduced ureA and GGE decreased alpA and cagA. HP7 significantly reduced flaA associated with $H$. pylori motility. Meanwhile, the HP7 complex mixture significantly reduced $H$. pylori virulence genes compared to PPE or GGE or HP7 alone (Fig. 2b).

\section{Anti-H. pylori antibody titer in serum}

To confirm the colonization of $H$. pylori in mice, the absorbance of IgG serum against $H$. pylori was also related to $H$. pylori colonization, so anti-Helicobacter IgG-1 serum levels were measured [31]. The serum antibody titers were elevated 4 weeks after $H$. pylori inoculation, to values of $1.48 \pm 0.06,0.94 \pm 0.07$, and $0.95 \pm 0.04$ in the $H$. pylori infection (Group C), positive control DGL (Group D), and H. pylori infection/L. paracasei.

HP7 + PPE + GGE (Group COM3) treatment groups, respectively, as compared with $0.25 \pm 0.01$ in control animals (Group NC) (Fig. 3).

These results indicated that $H$. pylori infection was significantly reduced by treatment with a complex mixture of L. paracasei HP7 containing extracts of PPE and GGE.

\section{Decrease of $H$. pylori colonization}

Repeated intragastric inoculation of $\mathrm{C} 57 \mathrm{BL} / 6$ mice treated with $H$. pylori $\left(1.0 \times 10^{9} \mathrm{CFU} /\right.$ mouse, three times) led to a positive reaction in the gastric mucosal campylobacter-like organism (CLO) test (Table 2). Positive percentages were increased 4 weeks after $H$. pylori inoculation, with values of $100 \%$ (CI 72.2-100),

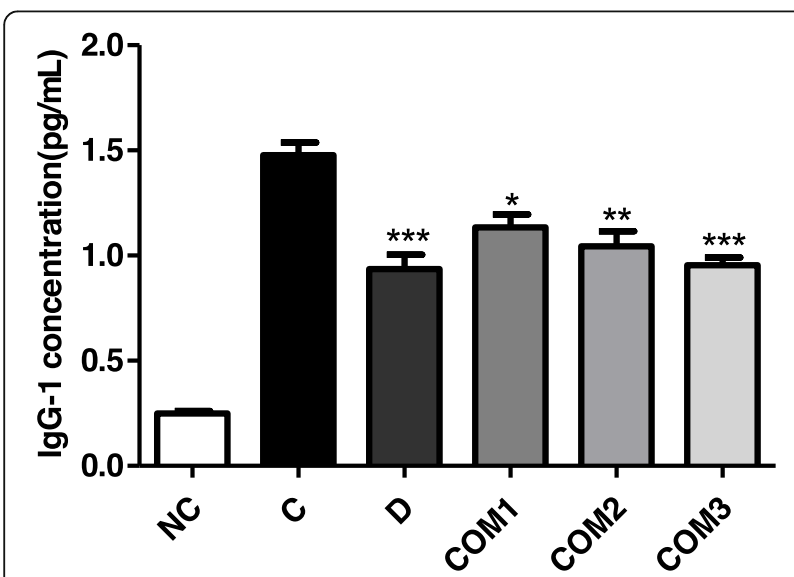

Fig. 3 Results of Helicobacter pylori antibody (lgG) test with mice serum. * Significantly different from the infection control Group $C(P<0.05)$. ** Significantly different from the infection control Group $C(P<0.01)$. ***Significantly different from the infection control Group $C(P<0.001)$
30\% (CI 10.8-60.3), $10 \%$ (CI 1.8-40.4) in the H. pylori infection (Group C), positive control DGL (Group D) and H. pylori infection/L. paracasei $\mathrm{HP7}+\mathrm{PPE}+$ GGE (Group COM3) treatment groups, respectively, compared with $0 \%$ (CI $0-27.6)$ in control animals (Group NC) (Table 2).

CLO scores were decreased by $H$. pylori infection/L. paracasei $\mathrm{HP7}+\mathrm{PPE}+\mathrm{GGE}$ (Group COM3) relative to H. pylori-infected animals without treatment (Group C) $(P<0.01$; Fig. 4). Therefore, L. paracasei $\mathrm{HP7}+\mathrm{PPE}+$ GGE may reduce the colonization rate of $H$. pylori.

Alleviation of gastric mucosal lesions caused by H. pylori Pathological changes in the gastric mucosa were minimal in animals not infected with $H$. pylori (Group NC). In contrast, Group C (H. pylori inoculated) mice exhibited gastric atrophy and severely shortened villi. However, mice in Group COM3 (H. pylori infected/L. paracasei $\mathrm{HP7}+\mathrm{PPE}+\mathrm{GGE}$ ) showed a significant improvement in gastric mucosa. These results were confirmed by an increase in villus length in Group COM3 compared with Group C (Fig. 5).

\section{Suppression of $H$. pylori-induced IL-8 production}

Blood IL-8 levels were elevated 4 weeks after $H$. pylori inoculation, with values of $7.39 \pm 0.70,5.73 \pm 0.63$, $5.16 \pm 0.49$ in the H. pylori infection (Group C), positive control DGL (Group D) and H. pylori infection/L. paracasei $\mathrm{HP7}+\mathrm{PPE}+\mathrm{GGE}$ (Group COM3) treatment groups, respectively, as compared to $5.36 \pm 0.59$ in control animals (Group NC) (Fig. 6).

\section{Discussion}

Lactic acid bacteria suppress the growth of human bacterial pathogens by secreting compounds, such as antibiotics, organic acids, and bacteriocins, to lower the $\mathrm{pH}$ of the environment and control gastrointestinal infections [31, 32]. The inhibitory activity of $H$. pylori has been reported in several Lactobacillus spp., including L. acidophilus [32], L. casei [33], L. johnsonii [34], L. reuteri [35], and L. salivarius [36].

A new Lactobacillus spp. isolated from kimchi by Korea Yakult Co. Ltd. was identified as L. paracasei and was named strain HP7. Kimchi is considered a healthy food as it is enriched in vitamins $\mathrm{A}, \mathrm{B}$, and $\mathrm{C}$, and is high in fiber, but also contains a number of lactic acid bacteria [37]. The two herbs selected in this study were $P$. frutescens var. acuta and G. glabra, which showed the strong antibacterial activity of $H$. pylori by measuring the Helicobacter antibacterial activity (growth suppression) in the extraction of natural product candidates through the inhibitory clear zone test of $H$. pylori (data not shown).

G. glabra (licorice) was reported to exhibit antimicrobial activity against several gram-negative and gram- 
Table 2 Reactivity in the CLO test of gastric mucosa from mice infected with H. pylori followed by treatment with L. HP7 and herbal extracts

\begin{tabular}{lllll}
\hline Group & Treatment & $\mathbf{n}$ & Positive ${ }^{\text {a }}$ & Therapeutic \% \\
\hline NC & Normal control & 10 & $0 \%, \mathrm{Cl}$ 0-27.6 & $100 \%, \mathrm{Cl72.2-100}$ \\
C & H. pylori & 10 & $100 \%, \mathrm{Cl} 72.2-100$ & $0 \%, \mathrm{Cl} 0-27.6$ \\
D & H. pylori + DGL & 10 & $30 \%, \mathrm{Cl} 10.8-60.3$ & $70 \%, \mathrm{Cl} 39.7-89.2$ \\
COM1 & H. pylori + PPE5 + GGE1.2 & 10 & $50 \%, \mathrm{Cl} 23.7-76.3$ & $50 \%, \mathrm{Cl} 23.7-76.3$ \\
COM2 & H. pylori + PPE10 + GGE1.2 & 10 & $30 \%, \mathrm{Cl} 10.8-60.3$ & $70 \%, \mathrm{Cl} 39.7-89.2$ \\
COM3 & H. pylori + HP7+ PPE10+ GGE1.2 & 10 & $10 \%, \mathrm{Cl} 1.8-40.4$ & $90 \%, \mathrm{Cl} 60.0-98.2$ \\
\hline
\end{tabular}

DGL Deglycyrrhizinated Licorice, HP7 L. paracasei HP7, PPE P. frutescens var. acuta extract, GGE Glycyrrhiza glabra extract

${ }^{a} A$ positive percentage reflects $H$. pylori colonization, which was observed as medium color change from yellow to red

${ }^{\mathrm{b}}$ Incidence (95\% confidential interval [CI]) was calculated using MiniTab statistical software

positive bacterial strains including $H$. pylori [38]. In addition, licorice also exerted beneficial effects against H. pylori through its antiadhesive properties [39]. Activity against ulcer and cancer, and clinical outcomes of $H$. pylori infection were also exhibited by licorice. The curative effect of deglycyrrhizinated licorice (DGL) on ulcers has been reported in vivo and in clinical studies [40-42], and the anticancer effect of licorice extract was shown in an in vitro study [43]. G. glabra was shown to possess anti-ulcerogenic properties that may be conferred by the cytoprotective mechanism of its antioxidant properties. These results supported the ethnomedical uses of licorice in the treatment of gastric ulcer [44].

Traditionally, P. frutescens var. acuta has been prescribed to treat depression- related disease, anxiety, asthma, chest stuffiness, vomiting, cough, cold, flu, phlegm, tumors, allergies, intoxication, fever, headache, stuffy nose, constipation, abdominal pain, and indigestion, and acts as an analgesic, anti-abortive agent, and a sedative [23]. The antibacterial activity of $P$. frutescens var. acuta has also been reported [24].

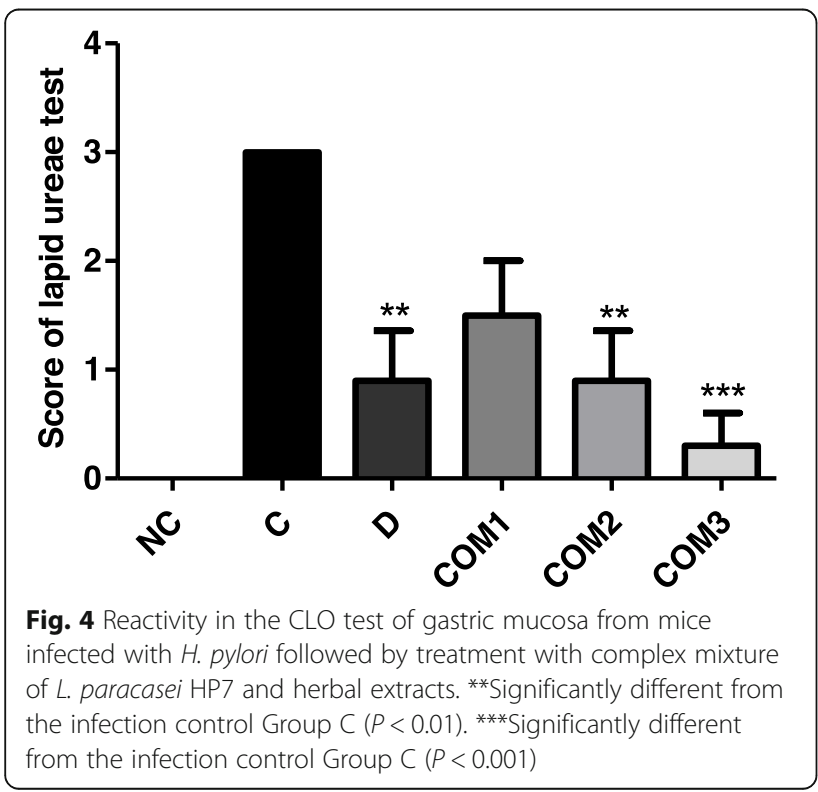

In this study, we confirmed in vitro and in vivo experiments of $H$. pylori inhibitory activity of a $L$. paracasei HP7 complex mixture containing $P$. frutescens var. acuta and G. glabra extracts. P. frutescens extract and G. glabra extract inhibited the growth of $H$. pylori in a dosedependent manner, and the H. pylori growth inhibitory effect was increased when the two extracts were mixed at $\mathrm{IC}_{50}$ concentration. In addition, the inhibitory effect of adhesion of gastric epithelial AGS cells of $H$. pylori by the L. paracasei HP7 or P. frutescens extract and G. glabra extract, when applied in a complex mixture, rather than each individually, was confirmed to be larger. Also, we confirmed the inhibitory activity of a complex mixture of $L$. paracasei HP7 including the extracts of $P$. frutescens and G. glabra against $H$. pylori in a mouse model; a rapid urease test of mouse stomachs showed decreased $H$. pylori colonization. Thus, the eradication of $H$. pylori reduced inflammation and epithelial damage in the stomach, although it is also possible that a complex mixture of $L$. paracasei HP7 including the extract of $P$. frutescens and G. glabra had direct antiinflammatory effects on the gastric mucosa.

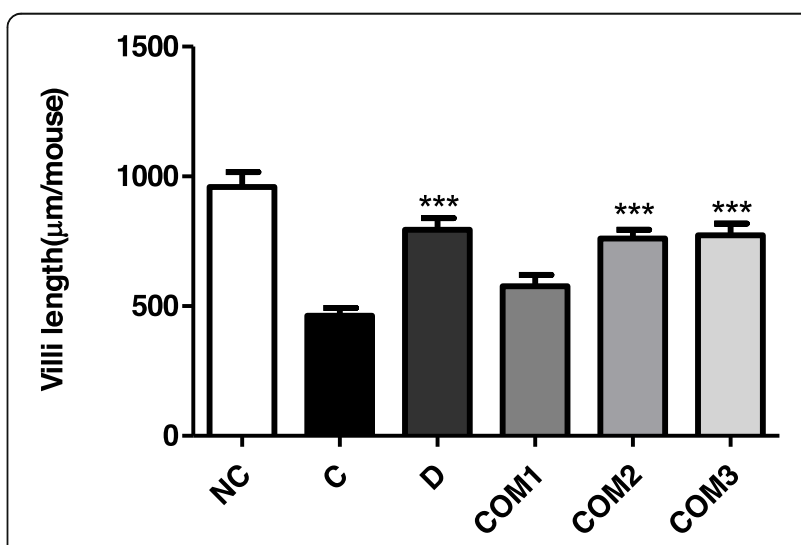

Fig. 5 Gastric mucosal vili lengths of mice infected with $H$. pylori followed by treatment with complex mixture of L. paracasei HP7 and herbal extracts. ${ }^{* *}$ Significantly different from the infection control Group $C(P<0.001)$ 


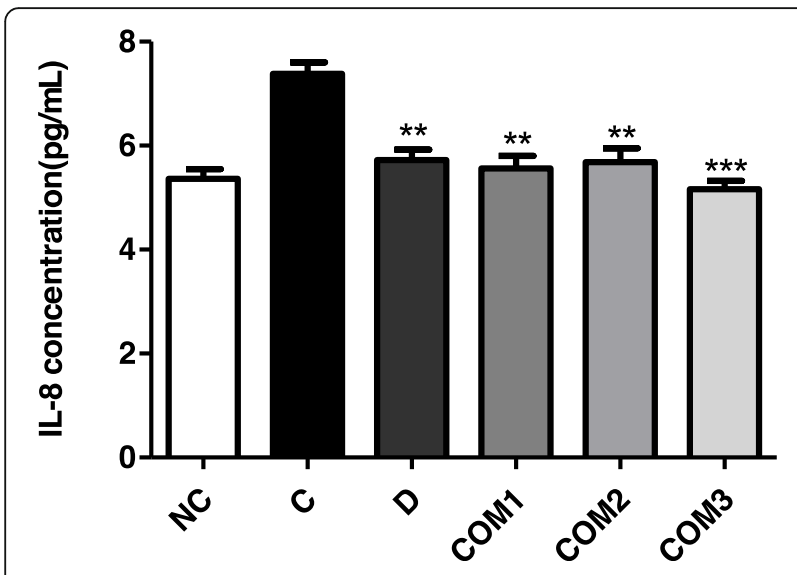

Fig. 6 Serum IL-8 levels of mice infected with H. pylori followed by treatment with complex mixture of $L$. paracasei HP7 and herbal extracts. **Significantly different from the infection control Group $C(P<0.01)$. ***Significantly different from the infection control Group $C(P<0.001)$

Although triple therapy consisting of two antibiotics and a proton pump inhibitor is effective over a short term and helps to maintain patient compliance, many patients experience undesirable side effects such as diarrhea, epigastric pain, nausea, and bloating [45].

In comparison, a complex mixture of L. paracasei HP7, including the extracts of $P$. frutescens and G. glabra, is safe and therefore appropriate for the prevention and treatment of $H$. pylori infection. In this study, the therapeutic effect of a complex mixture of $L$. paracase $\mathrm{HP7}$ including the extract of P. frutescens and G. glabra, was partial, at $90 \%$. However, H. pylori adhesion and a reduced inflammatory response was shown. Other researchers reported also that probiotics alone could not completely eliminate $H$. pylori, but could reduce the load of $H$. pylori in the stomach, and alleviate gastric mucosal inflammation [46, 47]. Accumulating evidence suggests an important role of IL-8 in H. pylori infection-associated chronic atrophic gastritis, peptic ulcer and gastric cancer [48]. The suppression of IL-8 by a complex mixture of $L$. paracasei HP7, including the extract of $P$. frutescens and G. glabra, can potentially prevent $H$. pylori-induced gastritis and carcinogenesis in the stomach.

Previously, the results of our study reported that $L$. paracasei HP7 alone was able, to some extent, suppress H. pylori infection [17]. This study was performed to confirm the elevation effect of compounds mixed with $P$. frutescens and G. glabra extract, which are known to have antibacterial and gastric mucosal protective effects other than L. paracasei HP7.

\section{Conclusions}

The administration of a complex mixture of L. paracasei HP7 containing an extract of P. frutescens and G. glabra was more effective than that of $L$. paracasei HP7 alone or P. frutescens extract or G. glabra extract, and the administration of a higher antibacterial effect of $H$. pylori and inflammation induced by $H$. pylori or it was confirmed to reduce the damage to the mucous membrane. The mechanism of this action resulted from the inhibitory effect of $L$. paracasei HP7 on the adhesion of $H$. pylori to the gastric mucosa, the antibacterial effect and antioxidative effect of G. glabra and P. frutescens extract, and the increased secretion of gastric mucosal mucin. It can be assumed that the anti-H.pylori effect and the protective effect on the gastric mucosa were induced. Thus, a complex mixture of $L$. paracasei $\mathrm{HP}$, including the extract of Perilla frutescens and Glycyrrhiza glabra can be used to treat patients with gastric symptoms, including ulcers caused by $H$. pylori.

These results demonstrated that treatment with a complex mixture of $L$. paracasei HP7, including the extract of $P$. frutescens and G. glabra could inhibit the growth of $H$. pylori and is thus a promising treatment for patients with gastric symptoms, such as gastritis, that are caused by $H$. pylori infection.

\section{Acknowledgements \\ The studies were suported Korea Yakult Co. Ltd.}

Authors' contributions

We confirmed all authors' contributions. The author(s) read and approved the final manuscript.

Funding

Funding information is not appicable.

Availability of data and materials

I declare that this manuscript has the availability of data and material.

\section{Competing interests}

I declare that this manuscript has no competing interests.

\section{Author details}

${ }^{1}$ Center for Animal Resources Development, Wonkwang University, 460 Iksandae-ro, Iksan 54538, Republic of Korea. ${ }^{2}$ R\&BD Center, Korea Yakult Co., Ltd., 22 Giheungdanji-ro 24 beon-gil, Yongin-si, Gyeonggi-do 17086, Republic of Korea.

Received: 6 August 2020 Accepted: 18 October 2020

Published online: 28 October 2020

\section{References}

1. Blaser MJ. Helicobacter pylori and the pathogenesis of gastroduodenal inflammation. J Infect Dis. 1990;161(4):626-33.

2. Everhart JE. Recent developments in the epidemiology of Helicobacter pylori. Gastroenterol Clin N Am. 2000;29(3):559-78.

3. Sugiyama A, Maruta F, Ikeno T, Ishida K, Kawasaki S, Katsuyama T, Shimizu N, Tatematsu M. Helicobacter pylori infection enhances N-methyl-N-nitrosoureainduced stomach carcinogenesis in the Mongolian gerbil. Cancer Res. 1998; 58(10):2067-9.

4. Maruta F, Ota H, Genta RM, Sugiyama A, Tatematsu M, Katsuyama T, Kawasaki S. Role of N-methyl-N-nitrosourea in the induction of intestinal metaplasia and gastric adenocarcinoma in Mongolian gerbils infected with Helicobacter pylori. Scand J Gastroenterol. 2001;36(3):83-90.

5. Asaka M, Sugiyama T, Kato M, Satoh K, Kuwayama H, Fukuda Y, Fujioka T, Takemoto T, Kimura K, Shimoyama T, Shimizu K, Kobayashi S. A multicenter, double- lind study on triple therapy with lansoprazole, amoxicillin and clarithromycin for eradication of Helicobacter pylori in Japanese peptic ulcer patients. Helicobacter. 2001;6(3):254-61. 
6. Salih BA, Abasiyanik MF, Saribasak H, Huten O, Sander E. A follow-up study on the effect of Helicobacter pylori eradication on the severity of gastric histology. Dig Dis Sci. 2005;50(8):1517-22.

7. Maruta F, Sugiyama A, Ishizone S, Miyagawa S, Ota H, Katsuyama T. Eradication of Helicobacter pylori decreases mucosal alterations linked to gastric carcinogenesis in Mongolian gerbils. J Gastroenterol. 2005;40(1):104-5.

8. Misiewicz JJ, Harris AW, Bardhan KD, Levi S, O'Morain C, Cooper BT, Kerr GD Dixon MF, Langworthy H, Piper D. One week triple therapy for Helicobacter pylori: a multicentre comparative study. Lansoprazole Helicobacter Study Group Gut. 1997:41(6):735-9.

9. Malfertheiner P, Megraud F, O'Morain CA, Atherton J, Axon AT, Bazzoli F, Gensini GF, Gisbert JP, Graham DY, Rokkas T, El-Omar EM, Kuipers EJ. European helicobacter study group. Management of Helicobacter pylori infection-the Maastricht IV/ Florence consensus report. Gut. 2012;61(5):646-64.

10. Midolo PD, Lambert JR, Turnidge J. Metronidazole resistance: a predictor of failure of Helicobacter pylori eradication by triple therapy. J Gastroenterol Hepatol. 1996:11(3):290-2.

11. Graham DY, Fischbach L. Helicobacter pylori treatment in the era of increasing antibiotic resistance. Gut. 2010;59(8):1143-53.

12. Megraud F, Coenen S, Versporten A, Kist M, Lopez-Brea M, Hirschl AM, Andersen LP, Goossens H, Glupczynski Y. Study group participants. Helicobacter pylori resistance to antibiotics in Europe and its relationship to antibiotic consumption. Gut. 2013;62(1):34-42.

13. Buenz EJ, Bauer BA, Schnepple DJ, Wahner-Roedler DL, Vandell AG, Howe $\mathrm{CL}$. A randomized phase I study of Atuna racemosa: a potential new antiMRSA natural product extract. J Ethnopharmacol. 2007;114(3):371-6.

14. Liu CS, Cham TM, Yang CH, Chang HW, Chen CH, Chuang LY. Antibacterial properties of Chinese herbal medicines against nosocomial antibiotic resistant strains of Pseudomonas aeruginosa in Taiwan. Am J Chin Med. 2007:35(6):1047-60.

15. Franceschi F, Cazzato A, Nista EC, Scarpellini E, Roccarina D, Gigante G, Gasbarrini G, Gasbarrini A. Role of probiotics in patients with Helicobacter pylori infection. Helicobacter. 2007;12(Suppl 2):59-63.

16. Kim MN, Kim N, Lee SH, Park YS, Hwang JH, Kim JW, Jeong SH, Lee DH, Kim JS, Jung HC, Song IS. The effects of probiotics on PPI-triple therapy for Helicobacter pylori eradication. Helicobacter. 2008;13(4):261-8.

17. Hong SS, Lee HA, Kim JY, Jeong JW, Shim JJ, Lee JL, Sim JH, Chung Y, Kim O. In vitro and in vivo inhibition of Helicobacter pylori by Lactobacilllus paracasei HP7. Lab Anim Res. 2018;34(4):216-22.

18. Kim DH, Kim YC, Choi UK. Optimization of antibacterial activity of Perilla frutescens var. acuta leaf against Staphylococcus aureus using evolutionary operation factorial design technique. Int J Mol Sci. 2011;12:2395-407.

19. Asha MK, Debraj D, Prashanth D, Edwin JR, Srikanth HS, Muruganantham N, Dethe SM, Anirban B, Jaya B, Deepak M, Agarwal A. In vitro anti-Helicobacter pylori activity of a flavonoid rich extract of Glycyrrhiza glabra and its probable mechanisms of action. J Ethnopharmacol. 2013;145(2):581-6.

20. Puram S, Suh HC, Kim SU, Bethapudi B, Joseph JA, Agarwal A, Kudiganti V. Effect of GutGard in the management of Helicobacter pylori: a randomized double blind placebo controlled study. Evid Based Complementary Altern Med. 2013;2013:263805.

21. Rahnama M, Mehrabani D, Japoni S, Edjtehadi M, Firoozi MS. The healing effect of licorice (Glycyrrhiza glabra) on Helicobacter pylori infected peptic ulcers. J Res Med Sci. 2013;18(6):532-3.

22. Yamamoto H, Ogawa T. Antimicrobial activity of perilla seed polyphenols against oral pathogenic bacteria. Biosci Biotechnol Biochem. 2002;66:921-4.

23. Ahmed HM. Ethnomedicinal, phytochemical and pharmacological investigations of Perilla frutescens (L.) Britt molecules. 2019;24(1):102.

24. Choi UK, Lee OH, Lim SI, Kim YC. Optimization of antibacterial activity of Perilla frutescens var. acuta leaf against Pseudomonas aeruginosa using the evolutionary operation-factorial design technique. Int J Mol Sci. 2010;11(10):3922-32.

25. Omer EA, Khattab ME, Ibrahim ME. First cultivation trial of Perilla frutescens $L$. in Egypt. Flavour Fragr J. 1998;13:221-5

26. Banno N, Akihisa T, Tokuda H, Yasukawa K, Higashihara H, Ukiya M, Nishino $H$. Triterpene acids from the leaves of Perilla frutescens and their antiinflammatory and antitumor-promoting effects. Biosci Biotechnol Biochem. 2004:68:85-90

27. Wang XF, Li H, Jiang K, Wang QQ, Zheng YH, Tang W, Tan CH. Antiinflammatory constituents from Perilla frutescens on lipopolysaccharidestimulated RAW264.7 cells. Fitoterapia. 2018;130:61-5.

28. Tsukasa M, Tetsufumi T, Haruki Y. A novel approach for screening of new anti-Helicobacter pylori substances. Biol Pharm Bull. 2008;31(1):143-5.
29. Selbach M, Moese S, Meyer TF, Backert S. Functional analysis of the helicobacter pylori cag pathogenicity island reveals both VirD4-CagA-dependent and VirD4CagA-independent mechanisms. Infect Immun. 2002;70(2):665-71.

30. Moon DI, Shin EH, Oh HG, Oh JS. Hong S, Chung Y, Kim O. usefulness of a Helicobacter pylori stool antigen test for diagnosing H. pylori infected C57BL/ 6 mice. Lab Anim Res. 2013;29(1):27-32.

31. Kreuning J, Lindeman J, Biemond I, Lamers CB. Relation between IgG and IgA antibody titres against Helicobacter pylori in serum and severity of gastritis in asymptomatic subjects. J Clin Pathol. 1994;47(3):227-31.

32. Rolfe RD. The role of probiotic cultures in the control of gastrointestinal health. J Nutr. 2000;130(2S Suppl):396S-402S.

33. Sgouras D, Maragkoudakis P, Petraki K, Martinez-Gonzalez B, Eriotou E, Michopoulos S, Kalantzopoulos G, Tsakalidou E, Mentis A. In vitro and in vivo inhibition of Helicobacter pylori by Lactobacillus casei strain Shirota. Appl Environ Microbiol. 2004;70(1):518-26.

34. Sgouras DN, Panayotopoulou EG, Martinez-Gonzalez B, Petraki K, Michopoulos S, Mentis A. Lactobacillus johnsonii La1 attenuates Helicobacter pylori-associated gastritis and reduces levels of proinflammatory chemokines in C57BL/6 mice. Clin Diagn Lab Immunol. 2005;12(12):1378-86.

35. Lionetti E, Miniello VL, Castellaneta SP, Magistá AM, de Canio A Maurogiovanni G, lerardi E, Cavallo L, Francavilla R. Lactobacillus reuteri therapy to reduce side-effects during anti-Helicobacter pylori treatment in children: a randomized placebo controlled trial. Aliment Pharmacol Ther. 2006:24(10):1461-8

36. Ryan KA, Daly P, Li Y, Hooton C, O'Toole PW. Strain-specific inhibition of Helicobacter pylori by Lactobacillus salivarius and other lactobacilli. J Antimicrob Chemother. 2008;61(4):831-4.

37. Ki MR, Ghim SY, Hong IH, Park JK, Hong KS, Ji AR, Jeong KS. In vitro inhibition of Helicobacter pylori growth and of adherence of cagA-positive strains to gastric epithelial cells by Lactobacillus paraplantarum KNUC25 isolated from kimchi. J Med Food. 2010:13(3):629-34.

38. Gupta VK, Fatima A, Faridi U, Negi AS, Shanker K, Kumar JK, Rahuja N, Luqman S, Sisodia BS, Saikia D, Darokar MP, Khanuja SPS. Antimicrobial potential of Glycyrrhiza glabra roots. J Ethnopharmacol. 2008;116(2):377-80.

39. Wittschier N, Faller G, Hensel A. Aqueous extracts and polysaccharides from Liquorice roots (Glycyrrhiza glabra L.) inhibit adhesion of Helicobacter pylori to human gastric mucosa. J Ethnopharmacol. 2009;125(2):218-23.

40. Larkworthy W, Holgate PF. Deglycyrrhizinized liquorice in the treatment of chronic duodenal ulcer. A retrospective endoscopic survey of 32 patients. Practitioner. 1975;215(1290):787-92.

41. Bennett A, Clark-Wibberley T, Stamford IF, Wright JE. Aspirin-induced gastric mucosal damage in rats: cimetidine and deglycyrrhizinated liquorice together give greater protection than low doses of either drug alone. J Pharm Pharmacol. 1980;32(2):151.

42. Jalilzadeh-Amin G, Najarnezhad V, Anassori E, Mostafavi M, Keshipour H. Antiulcer properties of Glycyrrhiza glabra L. extract on experimental models of gastric ulcer in mice. Iran J Pharm Res. 2015;14(4):1163-70.

43. Khazraei-Moradian S, Ganjalikhani-Hakemi M, Andalib A, Yazdani R, Arasteh J, Kardar GA. The effect of licorice protein fractions on proliferation and apoptosis of gastrointestinal Cancer cell lines. Nutr Cancer. 2017:69(2):330-9.

44. Mukherjee M, Bhaskaran N, Srinath $\mathrm{R}$, et al. Anti-ulcer and antioxidant activity of GutGard. Indian J Exp Biol. 2010;48(3):269-74.

45. Sakamoto I, Igarashi M, Kimura K, Takagi A, Miwa T, Koga Y. Suppressive effect of Lactobacillus gasseri OLL 2716 (LG21) on Helicobacter pylori infection in humans. J Antimicrob Chemother. 2001:47(5):709-10.

46. Salas-Jara MJ, Sanhueza EA, Retamal-Díaz A, González C, Urrutia H, García A. Probiotic Lactobacillus fermentum UCO-979C biofilm formation on AGS and Caco-2 cells and Helicobacter pylori inhibition. Biofouling. 2016;32(10):1245-57.

47. Song HY, Zhou L, Liu DY, Yao XJ, Li Y. What roles do probiotics play in the eradication of Helicobacter pylori? Current Knowledge and Ongoing Research Gastroenterol Res Pract. 2018:16:9379480

48. Lee KE, Khoi PN, Xia Y, Park JS, Joo YE, Kim KK, Choi SY, Jung YD. Helicobacter pylori and interleukin-8 in gastric cancer. World J Gastroenterol. 2013:19(45):8192-202.

\section{Publisher's Note}

Springer Nature remains neutral with regard to jurisdictional claims in published maps and institutional affiliations. 